\title{
A DINÂMICA GEOTECNOGÊNICA EM ÁREAS PERIURBANAS: MUNICÍPIO DE SÃO PEDRO (SP)
}

Resumo: O presente artigo objetiva analisar aspectos associados à dinâmica geotecnogênica ocorrente em áreas periurbanas afetadas por processos erosivos lineares. Foi escolhida como estudo de caso uma área do município de São Pedro SP (bacia hidrográfica do córrego Tucunzinho), devido ao fato de conter feições tecnogênicas associadas à recorrentes intervenções visando o controle de processos erosivos. O estudo se baseou na análise geomorfológica realizada a partir de mensuração topográfica de detalhe e monitoramento da evolução das feições durante o período de três anos, utilizando-se equipamento GPS modelo RTK. Como resultado constatou-se que o modelado tecnogênico têm atuado como contribuinte à dinâmica erosiva e a presença de depósito em cabeceira de voçoroca têm induzido o acentuado entulhamento do canal, intensificando o quadro de degradação ambiental mediante assoreamento à jusante.

Palavras-chave: Erosão Linear. Geotecnogênese. Análise Geomorfológica. Topografia de Detalhe. Geoprocessamento.

\section{THE GEOTECHNOGENIC DYNAMIC IN PERIURBAN ÁREAS: SÃO PEDRO COUNTY (SP)}

Abstract: This paper aims to analise the geotechnogenic dynamics occuring in periurban áreas afected by linear erosion processes. Was chosen to case study the area in the county of São Pedro - SP (basin of Tucunzinho stream) due to the fact contain tecnnogenic features associated with recurrent interventions for erosion control. The study was based on geomorphological analysis made from topographic detail measurement and monitoring the evolution of the forms during the three-year period, using GPS equipment model RTK. As a result it was found that the tecnogenic modeled has acted as a contributor to the dynamic erosive and the presence of the deposit in the gully headwater has induced the accumulation of the channel, increasing the environmental degradation framework by siltation downstream.

Keywords: Linear Erosion. Geotechnogenesis. Geomorphological Analisys. Topography of Detail. Geoprocessing.

\section{LA DINÁMICA GEOTECNOGÉNICA EN AREAS PERIURBANAS: MUNICIPIO DE SÃO PEDRO (SP)}

Resumen: El presente artículo objetiva analizar aspectos asociados a la dinâmica geotecnogénica ocurrente en áreas periurbanas afectadas por procesos erosivos lineales. Se eligió como estudio de caso un área del municipio de São Pedro - SP (cuenca hidrográfica del arroyo Tucunzinho), debido al hecho de contener formas

\footnotetext{
${ }^{1}$ Universidade Estadual Paulista, Departamento de Geografia, Presidente Prudente, Brasil, joao.o.nunes@unesp.br, https://orcid.org/0000-0003-3924-4056

2 Universidade Federal de Mato Grosso, Departamento de Geografia, Cuiabá, Brasil, denertm@yahoo.com.br, https://orcid.org/0000-0003-2997-0126
} 
tecnogénicas asociadas a las recurrentes intervenciones para el control de procesos erosivos. El estudio se basó en el análisis geomorfológico realizado a partir de la medición topográfica de detalle y monitoreo de la evolución de las formas durante el período de tres años, utilizando equipo GPS modelo RTK. Como resultado se constató que el modelado tecnogénico hay actuado como contributivo a la dinámica erosiva y la presencia de depósito en cabecera de barranco induce la acentuada acumulacion del canal, intensificando el cuadro de degradación ambiental mediante colmatación aguas abajo.

Palabras clave: Erosion lineal. Geotecnogénesis. Análisis Geomorfológico. Topografía de Detalle. Geoprocesamiento.

\section{Introdução}

As intervenções antrópicas no meio físico se evidenciam como alterações na fisionomia e fisiografia da paisagem, cujos resultados podem se traduzir em impacto negativo ao ambiente. São especialmente marcantes as alterações provocadas pela formação dos denominados depósitos tecnogênicos, que no contexto de áreas urbanas são gerados a partir da deposição de resíduos da construção civil, lixo doméstico e artefatos em geral que, juntamente com solos remobilizados, vão sendo construídos em áreas quase sempre inadequadas.

O conhecimento sobre a geração dos depósitos tecnogênicos, bem como de suas características têm sido de grande importância para o entendimento das diversas formas de uso e apropriação do relevo, e consequentemente suas derivações. Diversos autores estrangeiros vêm sistematizando tal conhecimento, dentre os quais se destacam Ter Stepaniam (1988), Waters, et al (2015), entre outros. No Brasil, destacam-se os trabalhos de Oliveira (1995) e Peloggia (1998; 2005).

Os pressupostos defendidos pelos citados autores apontam a atuação do homem como agente de profundas transformações ambientais, cujos produtos se evidenciam em formas de relevo e depósitos criados que se notabilizam face à dinâmica geológica/geomorfológica natural. Essa premissa endossa a proposição, defendida por diversos autores, de que o período geológico marcado pelo início dos processos derivados da ação antrópica deve ser individualizado dos precedentes, recebendo a denominação Tecnógeno, em referência à ação técnica promovida pelas atividades humanas (OLIVEIRA, 1995; PELOGGIA, 1998). 
Ao conjunto de níveis da ação transformadora do homem sobre o meio geológico é atribuída a designação geotecnogênese (PELOGGIA, 2005). Os fenômenos de caráter geotecnogênico se dão primeiramente a partir das alterações na fisiografia das paisagens, resultantes das modificações no relevo. Seguem-se as mudanças na dinâmica dos processos superficiais, entendidas como alterações na fisiologia das paisagens. Subsequentemente têm-se a criação de formas de relevo e formação de depósitos correlativos, similares e comparáveis aos formados por processos naturais do quaternário.

Aspecto essencial na identificação das alterações produzidas pela ação antrópica trata-se da categorização das formas e materiais associados à dinâmica geotecnogênica. A esse respeito, considera-se de grande importância a Classificação Integrada proposta por Peloggia (1999), aplicada especificamente aos depósitos tecnogênicos, que os categoriza segundo à gênese, composição, estrutura, forma de ocorrência e ambiente tecnogênico. Destes parâmetros, destacam-se a gênese e a composição, por serem os mais comumente adotados na caracterização dos depósitos.

Oliveira (1995, p. 233) classifica conforme a gênese três tipos principais de depósitos tecnogênicos: "construídos (aterros, corpos de rejeito etc.); induzidos (assoreamento, aluviões modernos, etc.) e modificados ("depósitos" naturais alterados tecnogenicamente por efluentes, adubos, etc)". Quanto à composição, de acordo com proposta de Fanning e Fanning (1989), adaptada por Peloggia (1999), estes podem ser classificados em: materiais úrbicos, que compreendem materiais terrosos com artefatos manufaturados (tijolo, plásticos, vidro, asfalto, pregos e outros), materiais gárbicos, compostos de detritos ricos em matéria orgânica (como o lixo orgânico), materiais espólicos, que são os materiais terrosos escavados e redepositados, e materiais dragados, que correspondem aos materiais terrosos provenientes de operações de dragagem.

No estudo dos processos tecnogênicos são também importantes as modificações que resultam na geração de morfologias "artificiais", expressas em formas produzidas pela mobilização das coberturas superficiais. Peloggia (1998) atribui a tais feições a designação de relevos tecnogênicos, os quais se constituem produtos do construtivismo, a exemplo dos terraços em nível comumente empregados como técnica mecânica para manejo do solo em áreas agrícolas.

Os relevos e depósitos tecnogênicos são, portanto, feições geomorfológicas de origem antrópica que irão interagir no ambiente, condicionando processos e 
atuando na mobilização de materiais, de forma a ocasionar respostas que muitas vezes se traduzem em impactos negativos.

Os aspectos geomorfológicos associados às intervenções humanas no meio físico são objeto de estudo da área denominada Antropogeomorfologia, cabendo aqui mencionar os trabalhos de Nir (1983) e Haff (2002), este último propondo ainda a adoção do termo New Geomorphology a tal campo de estudos. Rodrigues (2005), apresenta contribuição importante no que se refere ao mapeamento das alterações antrópicas e interpretação de suas derivações, dando enfoque aos impactos ambientais resultantes.

No tocante à fragilidade ambiental, merecem destaque as cabeceiras de drenagem em contato com áreas urbanas, as quais muitas vezes são marcadas pela presença de feições erosivas lineares. Quando os processos de erosão se encontram em estágio evolutivo avançado, configurando ravinas e voçorocas, se tornam motivo de preocupação por parte da administração pública, uma vez que impõe risco à estrutura urbana. Nesse estágio são imprescindíveis ações de caráter corretivo, embora comumente sejam tomadas medidas incipientes ou inapropriadas, tais como a deposição de resíduos sólidos urbanos, a qual se expressará na construção de um depósito tecnogênico.

A ausência de medidas eficazes de combate à erosão aliada às ações inapropriadas que buscam suprimir a evolução das feições erosivas, concomitantemente à disposição de resíduos, resulta em quadros de degradação que se refletem na qualidade de vida das populações em contato com tais áreas.

Este trabalho, portanto, parte do pressuposto de que os depósitos tecnogênicos ocorrentes em cabeceiras de ravinas e voçorocas constituem-se fator que intensifica o quadro de degradação, uma vez que se têm uma condição em que novos materiais são acrescentados e que, sob o dinamismo de processos erosivos ativos, tendem a ser carreados para os cursos d'água, aumentando a carga de sedimentos e, inclusive, de artefatos diversos.

\section{Estudo de caso}

O município de São Pedro, no interior do Estado de São Paulo, se caracteriza por apresentar feições que denotam diversos estágios evolutivos de processos erosivos. A presença de tais feições é associada primeiramente à predisposição física ao seu desencadeamento, a qual se somam as modificações 
antrópicas efetuadas na área, com destaque para o avanço da urbanização sobre áreas de fragilidade.

A área em questão está situada nos domínios da Bacia Sedimentar do Paraná, na região de contato entre a Depressão Periférica Paulista e as Cuestas Arenítico-basálticas, possuindo como arcabouço litológico predominante arenitos fluvio-lacustres e eólicos, respectivamente das Formações Pirambóia e Botucatu, a primeira datando do período Triássico e a segunda do Jurássico-Cretáceo. Cita-se ainda a ocorrência, capeando os topos dos interflúvios a partir de $550 \mathrm{~m}$ de altitude, de um pacote sedimentar, com espessura variando de alguns centímetros a 20 ou 30 metros, pertencente à Formação Rio Claro, de idade Neocenozóica (IPT, 1981; SANCHEZ, 1971; CARPI JUNIOR, 1996).

Distinguem-se solos associados à tal litologia, a saber, os Argissolos e Neossolos quartzarênicos, ambos apresentando-se bastante lixiviados e com grande suscetibilidade erosiva (SANCHEZ, 1971; CARPI JUNIOR, 1996).

As características geomorfológicas da área, de acordo com Mathias (2011), se definem pela ocorrência de topos com predomínio da forma tabular. As vertentes apresentam relevante comprimento de rampa, sendo que cedem abruptamente às margens dos córregos onde tem lugar a dinâmica erosiva atuante.

Em relação ao uso da terra, merece menção o fato de que o setor periurbano da bacia se caracteriza por apresentar pastagens degradadas, com notáveis manchas de solo exposto, denotando uso passado em atividade agropastoril. Atualmente verifica-se a tendência ao avanço da urbanização sobre tal área.

Neste trabalho definiu-se como recorte espacial a bacia hidrográfica do córrego Tucunzinho cuja principal característica geomorfológica é a presença de vultosa voçoroca, cujas dimensões aproximadas são de 700 metros de comprimento, largura variando entre 50 e 100 metros e profundidade de até 35 metros, contendo ainda ramificações na forma de sulcos e ravinas. A Figura 1a apresenta uma fotografia panorâmica da área, tomada em sobrevoo, na qual é possível identificar a mencionada feição erosiva e seu posicionamento em relação à malha urbana municipal. A Figura $1 \mathrm{~b}$ apresenta a fotografia da mesma a partir do solo. 
Fig. 1a e 1b - Voçoroca do córrego Tucunzinho a partir de vista aérea panorâmica e do solo, respectivamente.

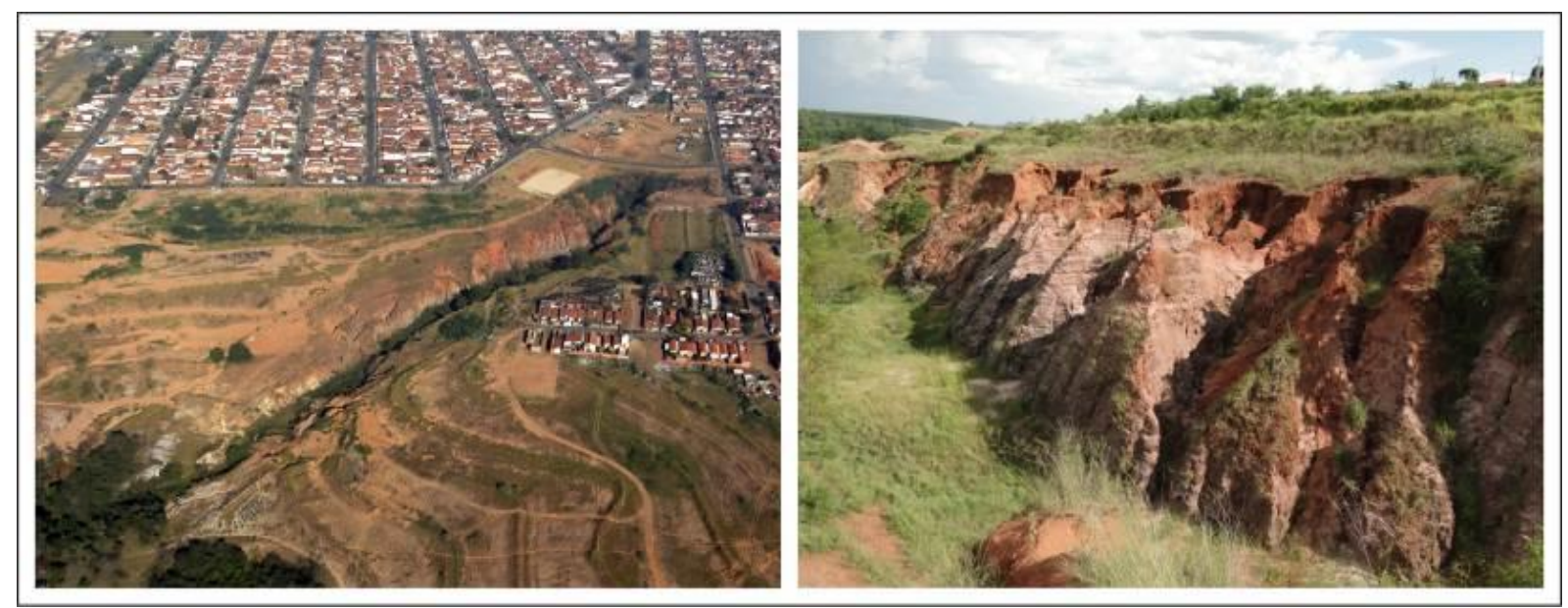

Fonte: Acervo de fotos do autor. Ano 2013.

Destaca-se na paisagem a presença de terraços em nível originados de obras pretéritas visando o controle dos processos erosivos. De acordo com Carpi Júnior (1996), tais obras, efetuadas no ano de 1992, se constituíram no soterramento das ravinas e voçorocas e o remodelamento do relevo. Salienta-se o caráter incipiente de tal intervenção, uma vez que se evidencia a ampla retomada da erosão.

Outra intervenção marcante é associada à estruturas de microdrenagem urbana instaladas na área em período concomitante às mencionadas obras. Tais estruturas compõem-se de redes de galerias pluviais que conduzem o fluxo do escoamento da área urbanizada para pontos de lançamento situados no baixo curso do córrego Tucunzinho. De acordo com Mathias (2016), as citadas estruturas apresentam problemas de dimensionamento e inadequação que contribuem para o desencadeamento erosivo, especialmente notável por acentuada erosão remontante nos pontos de lançamento.

Por fim, resta mencionar a ocorrência de deposição de resíduos sólidos urbanos no setor de cabeceira da voçoroca. Tais materiais compõem-se em sua maioria de entulho de construção civil, ocorrendo também artefatos diversos de uso doméstico e lixo. A disposição do citado depósito vêm a induzir uma resposta processual adversa à dinâmica erosiva da área, além de impôr uma condição sócioambiental degradante. 


\section{Método e técnicas}

Tendo como pressuposto teórico o método sistêmico, este trabalho desenvolveu-se a partir da análise geomorfológica efetuada sobre levantamento topográfico de detalhe e do monitoramento evolutivo das feições erosivas e deposicionais ocorrentes na área em sua totalidade. A fim de corroborar a importância que os depósitos de cabeceira têm sobre a dinâmica erosiva foram efetuadas mensurações topográficas no setor de ocorrência do depósito ao longo do período de três anos (de maio de 2013 a maio de 2015), com um ano de intervalo entre cada medição.

A técnica adotada para o levantamento topográfico de detalhe e a mensuração dos depósitos de cabeceira pautou-se no trabalho de Mathias (2016), que pressupõe o uso de equipamento GPS modelo RTK (L1/L2 Leica / GS15 Viva), cuja precisão na obtenção de dados permite a análise das feições em escala de detalhe.

O processamento dos dados deu-se em software de topografia (Autodesk Land) e seu mapeamento foi efetuado mediante a interpolação em ambiente SIG, através do programa ArcGIS 10.1. Foram elaborados Modelos Digitais do Terreno (MDT), a partir da criação de grades triangulares TIN.

A fim de se obter o volume do material depositado ao longo do período as grades foram convertidas em arquivos raster com resolução espacial de $0,1 \mathrm{~m}$. Em seguida, executou-se a subtração de uma superfície pela outra, a partir de operação com a ferramenta Cutfill, contida na toolbox 3D Analyst, que gerou a diferença entre as superfícies, expressa em unidades de volume $\left(\mathrm{m}^{3}\right)$.

A partir de observações de campo foi possível identificar a natureza dos materiais depositados, bem como a influência da formação do depósito na dinâmica da área, constatada pela interpretação das feições erosivas e deposicionais da voçoroca. Além disso, a análise das feições do modelado tecnogênico permitiu constatar fatos importantes ao entendimento dos processos.

\section{Resultados e discussão}

$\mathrm{Na}$ área da bacia hidrográfica do córrego Tucunzinho identificam-se dois tipos de feições tecnogênicas distintas (formas de relevo e depósitos), cada qual 
resultando em diferentes respostas processuais. As análises realizadas a partir do mapeamento das citadas feições e do monitoramento evolutivo preconizado neste estudo, evidenciam fatos importantes relativos à dinâmica de processos erosivos ocorrentes na área. Assim, tem-se que a sinergia entre os diferentes mecanismos envolvidos nos fenômenos (agradação/degradação) acarreta uma resposta complexa nas feições em desenvolvimento.

Nas vertentes do setor periurbano há o predomínio de formas de relevo resultantes de operações visando o controle erosivo, que se expressam em amplos terraços de base estreita. Embora constituam obstáculos ao escoamento superficial, tais feições têm proporcionado o acúmulo de água, mediante embaciamentos formados em sua porção anterior (montante). Este fato pode estar contribuindo com a redinamização dos processos erosivos mediante a percolação e consequente formação de fluxos de escoamento subsuperfical. A presença de dutos (piping) e franjas de capilaridade no sopé dos taludes erosivos constituem evidências a favor desta hipótese.

Outro aspecto que cabe mencionar refere-se à formação de rotas preferenciais ao escoamento, produzindo condições para a instalação de possíveis vetores de avanço erosivo. Foi possível identificar ramificações da voçoroca geradas após o colapso de terraços pela erosão remontante. Tendo-se rompido o terraço, o fluxo pluvial passa a desembocar em ravinamento, que evolui no sentido da rota de concentração do escoamento.

Ambos os fatos mencionados foram corroborados por observações em campo e as Figuras $2 \mathrm{a}$ e $2 \mathrm{~b}$ apresentam situações correspondentes a cada caso.

Fig. 2a e 2b - Efeitos da presença de terraços no relevo: acúmulo de água e geração de rota preferencial de fluxo do escoamento, respectivamente.

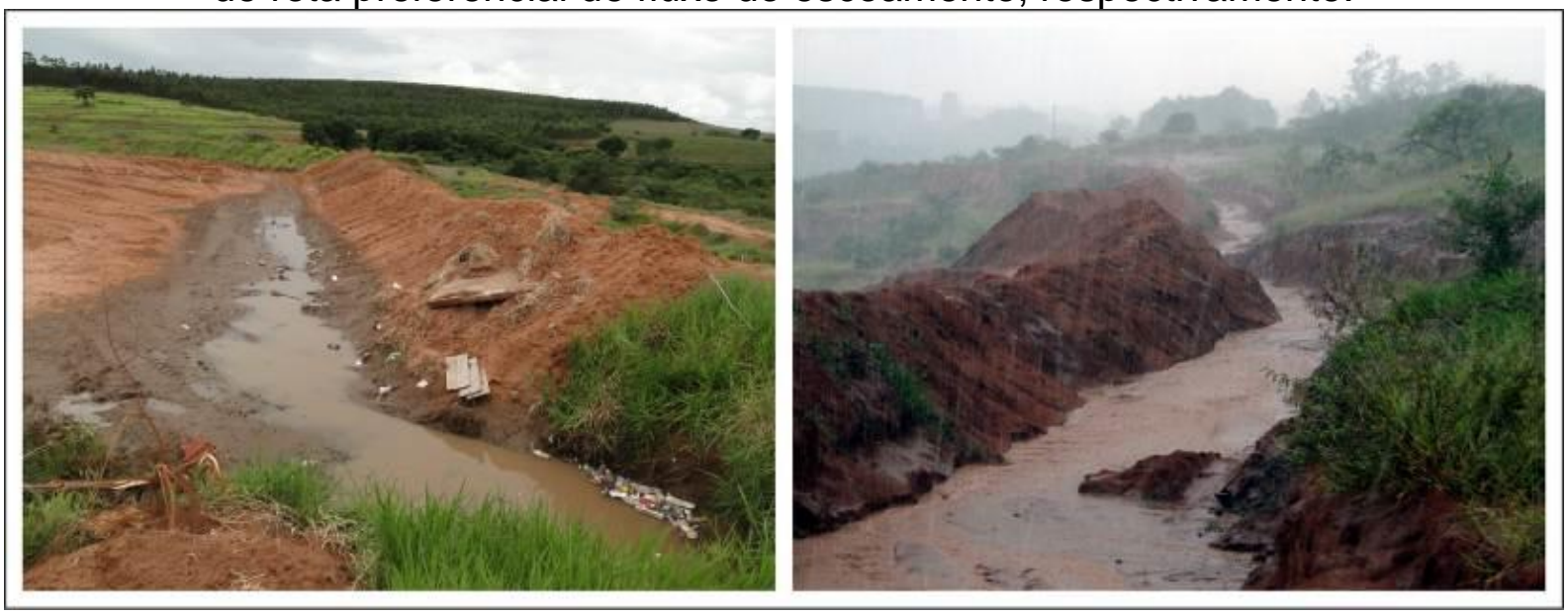

Fonte: Acervo de fotos do autor. Ano 2015. 
O modelado tecnogênico, portanto, responde à dinâmica dos processos de forma a contribuir com o avanço da erosão, excetuando-se algumas porções em que os terraços têm cumprido com o papel de retardo aos fluxos de escoamento, sendo contudo bastante pontuais. Como consequência constatam-se setores do talude erosivo que estão relativamente estabilizados, os quais contrastam com as porções de dinâmica mais intensa, expressa em ramificações da voçoroca na forma de sulcos e ravinas.

Quanto à feições deposicionais destaca-se o setor de cabeceira da voçoroca do córrego Tucunzinho, onde se localiza amplo depósito tecnogênico caracterizado por possuir composição mista em que constam em sua maioria, resíduos da construção civil. Secundariamente são identificados em quantidade expressiva restos vegetais e de tratos florísticos, assim como lixo doméstico variado, incluindose móveis, roupas e resíduos orgânicos. Esporadicamente são também lançadas carcaças de animais, como cães e gatos, contribuindo junto aos demais resíduos para a propagação de odores putrefatos. Tais materiais classificam-se como úrbicos e gárbicos, conforme terminologia expressa na literatura (PELOGGIA, 1998).

É importante mencionar que a deposição de resíduos se constitui parte da política da administração municipal, que têm investido nesta ação como método para contenção do avanço erosivo. Corroboram-se assim as afirmativas já citadas acerca das ações inapropriadas no tocante ao controle da erosão.

As Figuras $3 a$ e $3 b$ apresentam fotografias do referido depósito em dois períodos, no ano de 2013 e no ano de 2015, respectivamente, atestando seu acelerado crescimento.

Fig. 3a e 3b - Depósito no setor de cabeceira da voçoroca nos anos de 2013 e 2015, respectivamente.

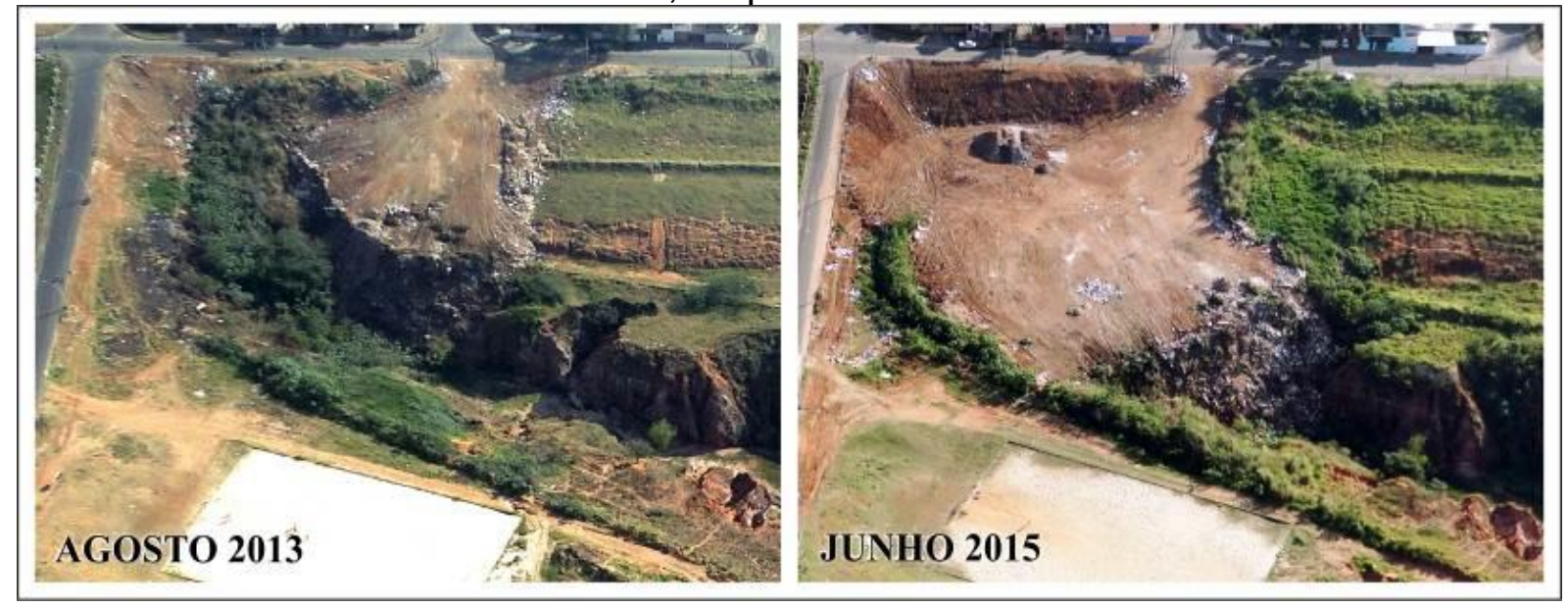

Fonte: Acervo de fotos do autor. 
No que concerne à dinâmica dos processos erosivos, a presença do citado depósito resulta em um quadro no qual, devido ao soterramento das feições, têm-se a dissimulação do avanço erosivo. Contudo, dado que os processos encontram-se ativos, a inserção de materiais acarreta o aumento da carga de fundo da voçoroca, mediante o transporte de um acentuado volume de detritos.

Os resultados obtidos a partir da quantificação do volume depositado apontam um volume de $45.038,8 \mathrm{~m}^{3}$ ao pacote de materiais formado ao longo do período de monitoramento. A título de comparação convém destacar que o referido valor é equivalente a 9007 caçambas de caminhão, cujo volume individual é de $5 \mathrm{~m}^{3}$. Essa equivalência é aproximada, dado que a compactação do material na composição do depósito (referida em engenharia civil como taxa de empolamento), resulta em um número superior de caçambas.

A Figura 4 apresenta o Modelo Digital da área, visualizado em perspectiva através do programa ArcScene 10.1, em que estão representados três momentos distintos, relativos a cada uma das etapas de mensuração efetuadas.

Fig. 4 - Modelo Digital do setor de cabeceira visto em perspectiva, dos anos de 2013, 2014 e 2015, respectivamente.

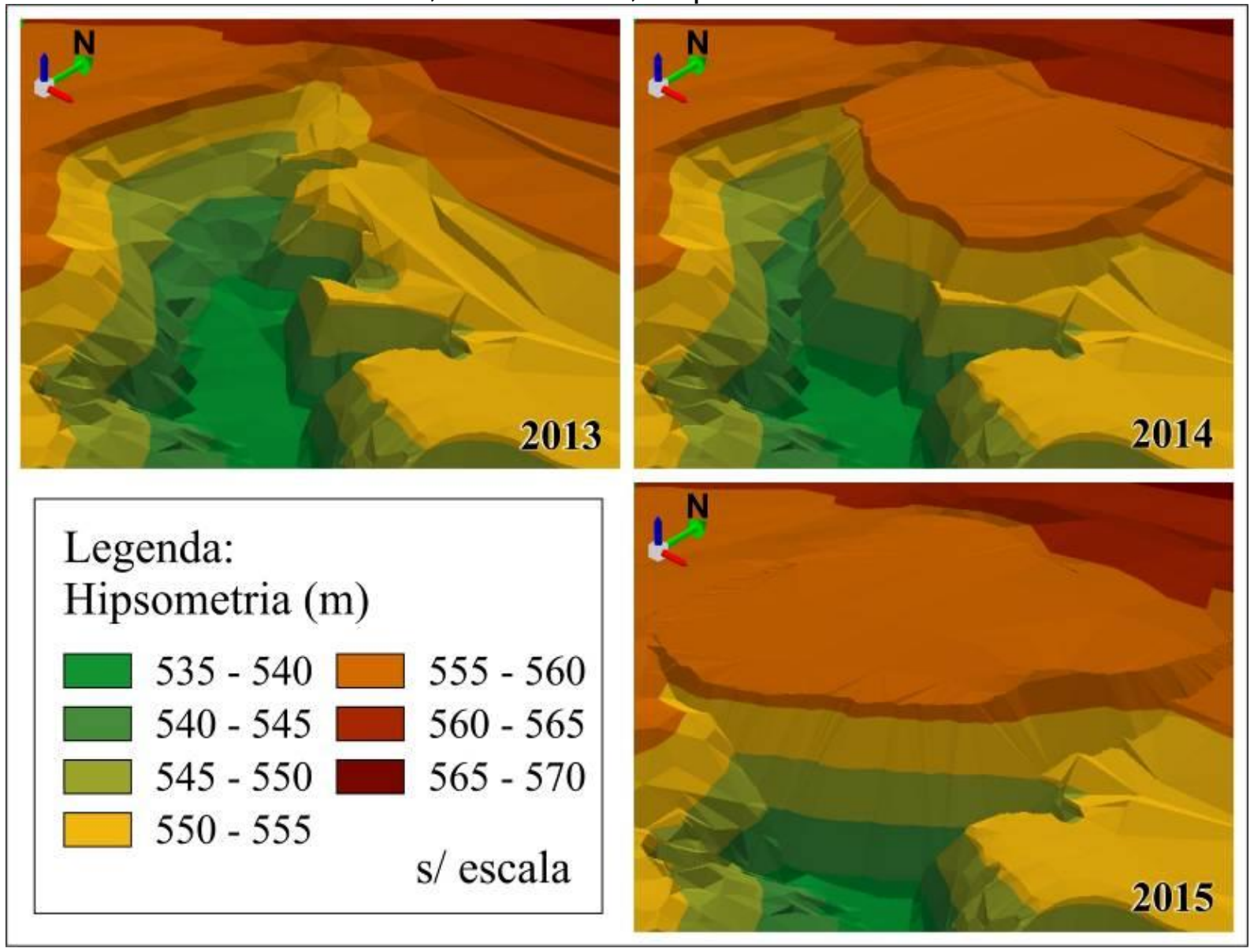

Fonte: Elaborado pelo autor. 
Aspecto intrínseco aos processos geotecnogênicos refere-se à velocidade com que se desenvolvem as feições na paisagem. Distinguem-se, portanto, dos processos naturais devido à inserção de uma curta escala temporal, em que as alterações no ambiente se dão de maneira veloz, assim como as respostas processuais a essas alterações.

A Figura 5 apresenta fotografias do setor de cabeceira tomadas do solo em um mesmo ângulo em quatro momentos distintos ( $A, B, C$ e $D)$, que permitem uma melhor apreciação das mudanças na paisagem da bacia ocorridas ao longo dos anos monitorados.

Fig. 5 (A, B, C e D) - Mudanças da paisagem no setor de cabeceira da voçoroca do córrego Tucunzinho em função da deposição tecnogênica.

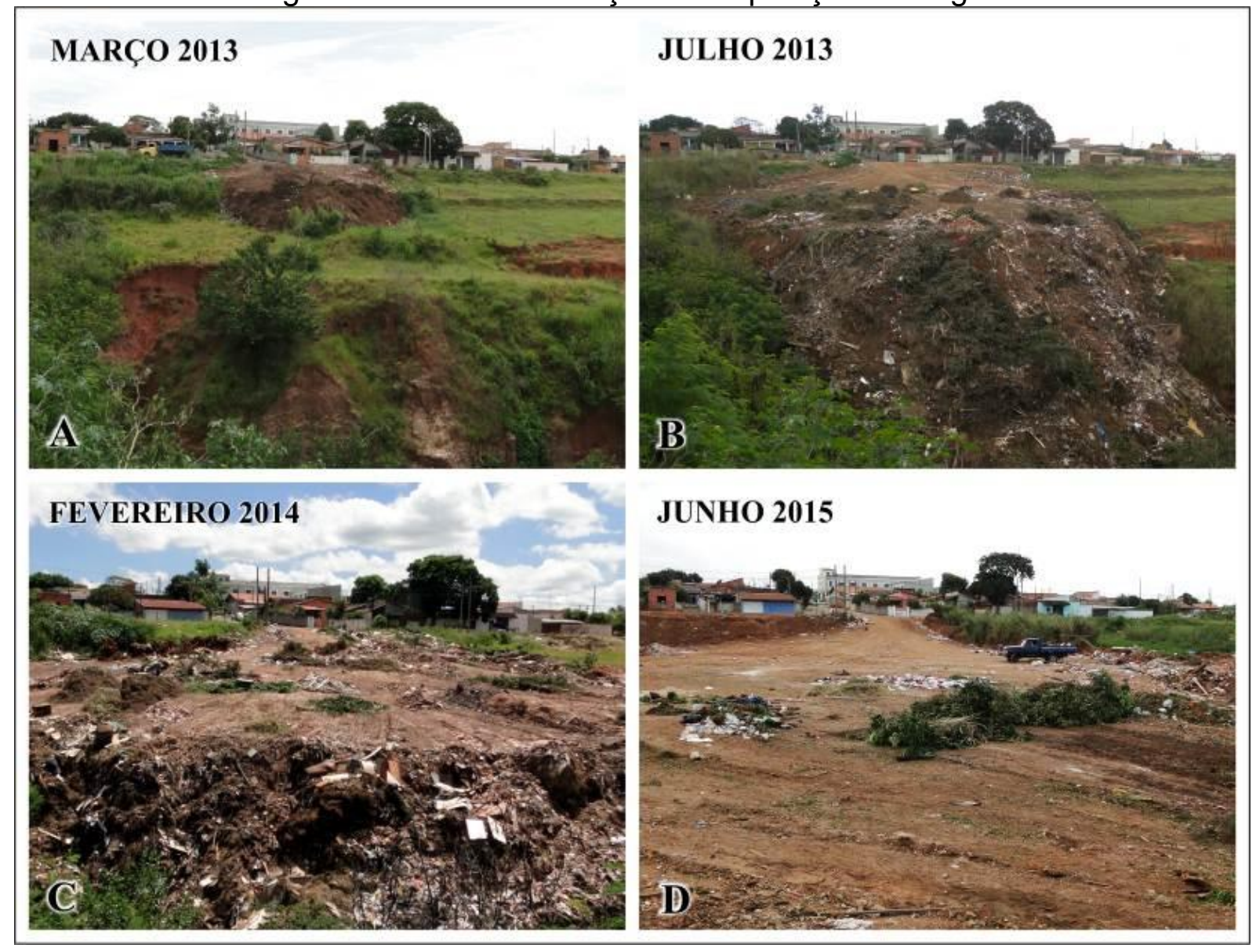

Fonte: Acervo de fotos do autor.

As observações efetuadas durante 0 período de monitoramento dos processos erosivos permitiram a constatação de que houve acréscimo no acúmulo de material no leito da voçoroca, associado à formação do depósito tecnogênico da cabeceira. Também foram identificados diversos artefatos transportados pelo 
escoamento superficial, sobretudo representados por lixo plástico e resíduos da construção civil.

As feições erosivas na bacia do córrego Tucunzinho são, portanto, afetadas pela dinâmica geotecnogênica, tanto por via do condicionamento exercido pela topografia (terraços) ao comportamento hidrológico da área, como pela constante deposição de detritos na cabeceira. Destes fatos resulta um quadro de intensas modificações na paisagem que se evidenciam em impactos negativos, expressos na reativação erosiva associada ao modelado tecnogênico e na acumulação de resíduos resultante da formação do depósito, com o consequente assoreamento dos cursos d'água à jusante da bacia.

Cabe ressaltar que a dinâmica dos processos erosivos na área estudada é influenciada por um conjunto de fatores físicos, em que se destaca a predisposição natural dos terrenos à incidência da erosão. As intervenções antrópicas vêm a se constituir um elemento adicional no desencadeamento dos processos, atuando por meio de um elenco de fatores tais como: o desmatamento, o mal uso da terra, a urbanização de planejamento incipiente ou ausente e, por fim, as medidas de controle à erosão ineficazes ou inapropriadas.

\section{Considerações Finais}

Os resultados apresentados neste estudo permitem afirmar que a dinâmica geotecnogênica associada às intervenções na bacia hidrográfica do córrego Tucunzinho têm colaborado com a intensificação de processos erosivos e gerado quadros de degradação ambiental. Tal afirmação se baseia na ideia de que as medidas de controle à erosão efetuadas na área são incipientes e/ou inadequadas, o que é respaldado pelos seguintes fatos:

a) Os terraços em nível apesar de concebidos visando o controle do comportamento hidrológico têm atuado como contribuintes à evolução das feições erosivas, tanto por fomentar o incremento de fluxos subsuperficiais (piping), mediante a retenção de água nas vertentes, como por gerar rotas preferenciais de escoamento que funcionam como possíveis vetores de avanço da erosão;

b) A constante inserção de materiais formando depósito tecnogênico em cabeceira de voçoroca impõe uma nova configuração à dinâmica erosiva, caracterizada pela dissimulação dos processos e geração de grande 
quantidade de detritos que resulta no atulhamento do leito e consequente assoreamento dos canais fluviais à jusante.

c) A deposição de resíduos em área de manancial evidencia-se como ação que acarreta impactos negativos expressos na contaminação de cursos d'água e aquíferos, e geração de condições de insalubridade à população em contato com tais depósitos.

A atuação conjunta de mecanismos degradacionais (erosão) e agradacionais (deposição tecnogênica), gera uma resposta processual complexa no contexto das feições erosivas. Tal fato se evidencia como uma especificidade do ambiente antropizado, no qual o sistema físico encontra-se marcado pela interação entre formas, materiais e processos tecnogênicos, configurando com isso uma morfodinâmica diferenciada.

\section{Agradecimentos}

À Fundação de Amparo à Pesquisa do Estado de São Paulo (FAPESP) pelo financiamento do projeto que resultou nos dados apresentados neste artigo.

\section{REFERÊNCIAS}

CARPI JUNIOR, S. Técnicas cartográficas aplicadas à dinâmica da bacia do Ribeirão Araquá - SP. 1996. 188 f. Dissertação (Mestrado em Geografia) - Instituto de Geociências e Ciências Exatas, Universidade Estadual Paulista, Rio Claro. 1996.

FANNING, D.J.; FANNING, M. C. B. Soil: morphology, genesis and classification. New York, John Wiley \& Sons, 1989. 395p.

HAFF, P. K. Neogeomorphology. Eos, Transactions American Geophysical Union, v. 83, n. 29, p. 310-317, 2002.

INSTITUTO DE PESQUISAS TECNOLÓGICAS DO ESTADO DE SÃO PAULO. 1981. Mapa geológico do Estado de São Paulo; escala 1:500.000. v1 (texto) e v2 (mapa). Governo do estado de São Paulo. Secretaria da Indústria, Comércio, Ciência e Tecnologia.

MATHIAS, D. T. Propostas de recuperação de áreas peri-urbanas erodidas com base em parâmetros hidrológicos e geomorfológicos: Córrego Tucunzinho (São Pedro/SP). 2011. 128 f. Dissertação (Mestrado em Geografia). Instituto de Geociências e Ciências Exatas, Universidade Estadual Paulista, Rio Claro, 2011.

MATHIAS, D. T. Contribuição metodológica para o diagnóstico da dinâmica erosiva linear e seu prognóstico evolutivo visando subsidiar projetos de recuperação. 2016. 178 f. Tese (Doutorado em Geografia). Faculdade de Ciências e Tecnologia, Universidade Estadual Paulista, Presidente Prudente, 2016. 
NIR, D. Man, a geomorphological agent: An introduction to anthropic geomorphology. Keter, Jerusalem and Reidel, Dordrecht, 1983.

OLIVEIRA, A. M. S. A abordagem geotecnogênica: a Geologia de Engenharia no Quinário. In: BITAR, O. Y. Curso de Geologia aplicada ao meio ambiente - DIGEO - IPT, São Paulo, ABGE, 1995. p. 231-241.

PELOGGIA, A. O homem e o ambiente geológico: geologia, sociedade e ocupação urbana no município de São Paulo. São Paulo: Xamã, 1998. 241 p.

PELOGGIA A. U. G. Sobre a classificação, enquadramento estratigráfico e cartografação dos solos e depósitos tecnogênicos. In: PELOGGIA A.U.G. Manual Geotécnico: Estudos de Geotécnica e Geologia Urbana. São Paulo, 1999. p. 35-50.

PELOGGIA, A. U. G.; OLIVEIRA, A. M. S. Tecnógeno: um novo campo de estudos das Geociências. In: CONGRESSO DA ASSOCIAÇÃO BRASILEIRA DE ESTUDO DO QUATERNÁRIO, Guarapari, 2005. Anais... ABEQUA: Guarapari, v. 10, 2005. 1 CD-ROM.

RODRIGUES, C. Morfologia original e morfologia antropogênica na definição de unidades espaciais de planejamento urbano: exemplo na metrópole paulista. Revista do

Departamento de Geografia, (17), p. 101-111, 2005.

SANCHEZ, M. C. Contribuição ao conhecimento das bases naturais dos municípios de São Pedro e Charqueada (SP). Notícia Geomorfológica: Campinas, Vol 11 (21), p: 47-60, 1971.

TER-STEPANIAN, G. 1988. Beginning of the Technogene. Bulletin I.A.E.G., 38:133-142.

WATERS, C. N. et al. The Anthropocene is functionally and stratigraphically distinct from the Holocene. Science, v. 351, n. 6269, p. aad2622, 2016. Disponível em:

http://science.sciencemag.org/content/351/6269/aad2622

Acesso em: 10 abr. 2016.

\section{NOTAS DE AUTOR}

\section{CONTRIBUIÇÃO DE AUTORIA}

Dener Toledo Mathias - Concepção. Coleta de dados, Análise de dados, Elaboração do manuscrito e revisão. João Osvaldo Rodrigues Nunes - Coleta de dados, Participação ativa da discussão dos resultados; Revisão e aprovação da versão final do trabalho.

\section{FINANCIAMENTO}

Fundação de Amparo à Pesquisa do Estado de São Paulo, Bolsa de Doutorado: Processo FAPESP no 2012/03745-4.

\section{CONSENTIMENTO DE USO DE IMAGEM}

Não se aplica.

\section{APROVAÇÃO DE COMITÊ DE ÉTICA EM PESQUISA}

Não se aplica. 
Este artigo está licenciado sob a Licença Creative Commons CC-BY. Com essa licença você pode compartilhar, adaptar, criar para qualquer fim, desde que atribua a autoria da obra.

\section{HISTÓRICO}

Recebido em: 12-04-2016

Aprovado em: 26-09-2018 